\title{
Exploring the Patterns of Resident Resettlement in Rural and Suburban Areas and Their Influence on the Passenger Trip Generation
}

\author{
Mykhailo Krystopchuk ${ }^{1,2}$, Tatiana Krystopchuk¹, Igor Khitrov,2, Igor Bugayov³, Dmytro Burko3, \\ Andrii Galkin ${ }^{3 *}$

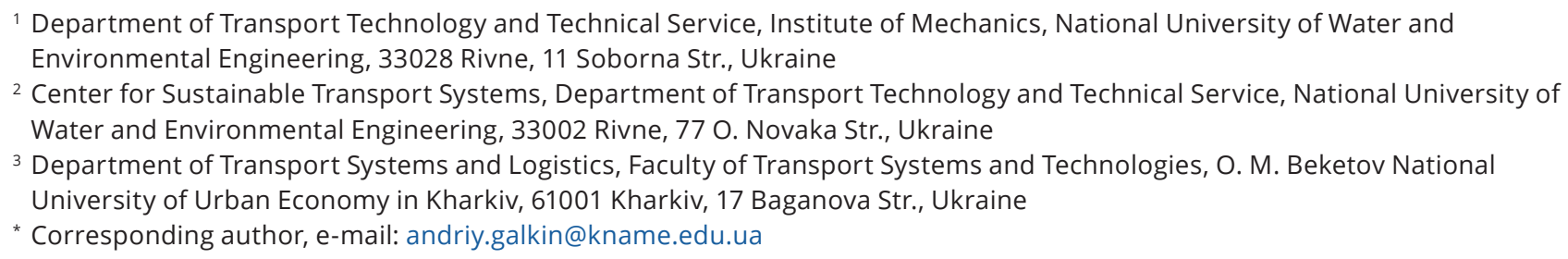

Received: 04 January 2020, Accepted: 31 January 2020, Published online: 03 January 2022

\begin{abstract}
The region is a complex multi-element and heterogeneous dynamic system. Regional public transport systems are characterized by heterogeneity and incompleteness of information about the processes that take place in them. The factors determining the demand for public passenger transport services, the structure of suburban population transit and the economic consequences of changing this structure have not yet been sufficiently investigated. There is no quantitative assessment of the control factors' influence on the results of the passenger transport system functioning in suburban traffic, which complicates the effective management in this field. In order to determine the mutual influence of objects with unclear functional connection, one of the methods of computational geometry is considered, which allows quantifying and obtaining tabulated functions of various components and parameters of settlements' interaction and centers of gravity. The numerical characteristics obtained by the described method are further used in the modeling of the processes of efficient functioning and collaboration of urban passenger transport with other external transport types, in particular at interchanges.

As a result of the proposed operations, we obtain a tabulated function of the investigated parameter for the area of spatial interaction of infrastructure objects and visualize the calculated parameters in the form of graphical dependencies or in the form of a threedimensional surface. Thus, using the method of computational geometry, with constructing a Voronoi diagram and executing the Delaunay triangulation, it is possible to obtain tabulated characteristic parameters for inhomogeneous zones of mutual influence where infrastructure objects with unclear functional connection are located.
\end{abstract}

\section{Keywords}

transport system, settlement patterns, passenger trips, suburban areas, regular model, Voronoi diagram, Delaunay triangulation

\section{Introduction}

The problem of efficient functioning of public road transport is an important part of a comprehensive social development program. Its successful solution depends on the transport system's degree of perfection and validity. Comprehensive studies of the transport services market formation patterns are based on studies of resettlement processes and spatial self-organization of the population, determination of the transport links density, nodes of origin and passenger flows elimination.
The feasibility of different destinations, depending on their range, is perceived differently by the agglomeration population (Cordera et al., 2018; Krystopchuk, 2012; Kujala et al., 2018; Oliveira et al., 2011; Schlosser, et al., 2019; Vakulenko et al., 2019). Each rural and suburban settlement is located among many other rural and urban settlements with an individual set of social, cultural and production potential in quantitative and qualitative terms. With developed road network and transport system, the population 
chooses the center of gravity, taking into account the restrictions imposed by this transport system and based on subjective considerations about the service quality. In addition, there are urgency factors of achieving the goal and intensity of the daily time balance (Galkin et al., 2019; Khitrov et al., 2019; Krystopchuk, 2012; Makarova et al., 2017).

However, a qualitative assessment of population trends can be given. The hierarchical significance of the city in the settlement system has a clear impact on the population's assessment of the appropriateness of the spatial choice of location to meet the purpose of the trip (Almetova et al., 2019; Amavi et al., 2014; Cremer and Keller, 1987). The higher it is, the more time in the daily balance of the rural and suburban population is allocated for resettlement.

Today, mathematical models that reveal the underlying causes and trends of resettlement are not perfect, given the multifactoriality of the process. A rational route network construction for servicing settlements located around a dominant center of gravity, which can be accepted as an administrative division (regional, district centers) or town with existing city-forming enterprises with the need for workers from the surrounding suburban areas, is possible provided the establishment of the patterns of forming passenger trips in cooperation with the urban core. In this case, harmonization of demand for transport services with the offer of such services will allow achieving efficient vehicles and transporting infrastructure use taking into account the real needs of the certain region population.

\section{Literature review}

\subsection{Modern approaches and methods of passenger's trips distribution analysis}

The criteria for evaluating the transportation systems' performance are described in detail in the many researches works (Cordera et al., 2018; Cremer and Keller, 1987; Krystopchuk, 2012; Kujala et al., 2018; Oliveira et al., 2011; Vakulenko et al., 2019). Methods of designing transport systems were reflected in the works for static models and dynamic models (Cremer and Keller, 1987; Galkin et al., 2018; de Dios Ortúzar and Willumsen, 2011; Saka, 2001; Stepanchuk et al., 2016; Tkhoruk et al., 2019). The disadvantage of static models is that they optimize the transport system relative to random resettlement, resulting in estimated transport loads that can be significantly different from the actual ones.

Dynamic models take into account changes in the transport system related to the factors "origin - destination", but do not provide a unique algorithm for finding its structure (Abdel-Aal, 2014; Cordera et al., 2018). There are well-known approaches in which the researches (Cremer and Keller, 1987; Kujala et al., 2018; de Dios Ortúzar and Willumsen, 2011; Thériault and Des Rosiers, 2013) consider the travels' assigning according to Poisson's distribution; note the multifactorial nature of the model for the public trip generation, and therefore the population mobility, and propose using the principle of maximizing entropy (Krystopchuk, 2012; de Dios Ortúzar and Willumsen, 2011).

In order to build an effective public passenger transport network taking into account the travel demand scientists (Kujala et al., 2018) use the alternative trips analysis based on the Pareto optimality principle. In the work (Cordera et al., 2018), the possibility of applying computational geometry methods (Oliveira et al., 2011; Pucher and Renne, 2005) to transform geodata on spatial and other characteristics (population density, household size, motorization level) of settlements in travel generation, and population mobility is noted. Thus, the analysis of known synthesis methods of transport systems indicates the need for their improvement, as well as the development of new methods, algorithms for designing and evaluating the efficiency and functioning reliability of existing transport systems and route networks (Tkhoruk et al., 2019), including suburban passenger traffic. Comprehensive research of the patterns governing motor transport services generation potential is based on studies of the resettlement processes and spatial self-organization of the population, determining the transport links' density, nodes of origin, transit trip elimination and passenger flows (Cremer and Keller, 1987; de Dios Ortúzar and Willumsen, 2011; Saka, 2001).

\subsection{Spatial distribution of labor and cultural ties}

Under resettlement we mean the population's distribution within a certain territory: country, region, etc. Resettlement is characterized by the total population $H_{F}$ living within a territory with an area $F$ or population density $h_{F}$ (Davidich et al., 2020; Krystopchuk, 2012).

The patterns of population resettlement are determined by the displacements they have implemented. According to the statement of the problem of resettlement analysis will be the travel distance $l$ or the time $t$ spent on moving relative to certain centers of gravity.

There are known models (Khitrov et al., 2019; Krystopchuk, 2012), for which, in the settlement zone $i$ the total displacements number of population of a certain group is equal to $A_{i}$ (Fig. 1). 


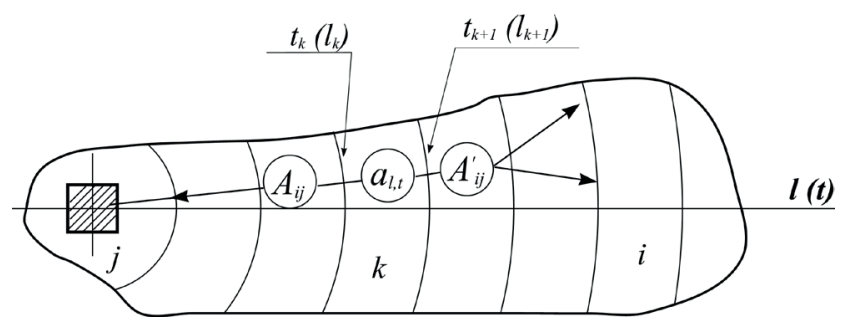

Fig. 1 Model for determining the density of transport links

This value is called the capacity of the zone with the departures. Similarly, the travel number that end in the zone $j$ is called the capacity upon arrival (it can be any center of gravity, or zone). Having taken for the center of construction a certain gravity center $j$, which is located in the $i$-th zone, the isochrones $t$, or isodistants $l$, are constructed with respect to it. The resettlement patterns are a consequence of the spatial self-organization patterns of the population in terms of time spent on displacement. Crucial in this is labor activity.

Different authors have proposed empirical and theoretical dependencies $d_{F}(l, t)$. In particular Krystopchuk (2012), suggested a normal-probability resettlement function of urban population, taking into account the multifactorial nature of forming links with gravity centers.

An exponential resettlement model has also become widespread (Davidich et al., 2020; Krystopchuk, 2012). One of the main generalized patterns of spatial distribution of labor and cultural ties is the dependence of their intensity on the distance of movement. According to research (Oliveira et al., 2011; Vakulenko et al., 2019), the desire to localize interests in as small area as possible is obvious. With a probability $p>0.95$, it can be argued that the rural and suburban population limits its movement within a radius $R_{n} \leq 50 \mathrm{~km}$, although there is a trend for displacement of $100 \mathrm{~km}$ or more.

Labor links make it possible to identify three zones in relation to rural and suburban gravity centers (Oliveira et al., 2011; Vakulenko et al., 2019). The first zone with $R_{n}<20 \mathrm{~km}$ is characterized by stable connections over a long period. The probability of having stable bonds in this case is $p \geq 0.8$. In this case, there is a steady labor interconnection process, which is virtually unaffected by random factors. As a consequence, there are no significant fluctuations in the passenger flow of commuters to work. In the second zone $\left(20 \leq R_{n} \leq 30 \mathrm{~km}\right)$, the probability is $p=0.5$, i.e., the employment relationships are not constant over time, their intensity varies significantly from year to year. Finally, the peripheral zone $\left(R_{n}>30 \mathrm{~km}\right)$ is characterized by occasional, low-intensity labor connections.
The appropriateness of different targeted movements, depending on their range, is perceived differently by the agglomeration population. Each rural and suburban settlement is located among many other settlements with an individual social, cultural and production potential set in quantitative and qualitative terms. With the developed road network and transport system, the population chooses the gravity center, considering the restrictions imposed by this transport system, and based on subjective considerations about the service quality. Moreover, the capacity of pedestrian flows are irregular during the rush hour and depend on the average travel time, then in suburban movements the highest values of flows will be observed at the moment of public transport departure. Evaluating the transport system functioning it's necessary to take into consideration pedestrian network. In addition, there are urgency factors of achieving the goal and intensity of the daily time balance. However, a qualitative assessment of population trends can also be given.

The hierarchical significance of the city in the settlement system has a clear impact on the population's assessment of the spatial choice appropriateness of location to meet the purpose of the trip (Oliveira et al., 2011; Vakulenko et al., 2019). The higher it is, the more time in the daily balance of the rural and suburban population is allocated for resettlement. The interconnection of settlements is limited mainly by neighboring settlements (with some exceptions to business and guest travel).

The distribution of urban displacement into rural and suburban settlements is influenced by the city size, the displacement range, the displacement's purpose, that is, the same factors as the villagers' displacement into cities. The difference is that the radius of urban displacement is much smaller. Thus, the intensive and regular movement zone in the working day cycle covers only the nearest areas with a radius up to $15 \mathrm{~km}$. During the weekends this zone's radius expands approximately $1.5-2$ times due to guest trips and rest trips.

Rural and suburban displacements' spatial distribution analysis shows that each settlement has an -dimensional spatial orientation, that is, each unit is characterized by a one-dimensional intensities distribution $P_{i j}: P_{11}, P_{12}, \ldots$, $P_{1 l}, \ldots, P_{1 k}$, where $P_{11}$ - the links within the settlement in question or other elementary unit of rural and suburban territories; $2, \ldots, l, \ldots, k$ - are the other units set that are connected (including urban settlements).

Based on the distribution of bonds, one can obtain the scattering field of the initial and destination points. Since 
the density of their dispersion in relation to the settlements is the same, then on their set it is possible to distinguish the territorial units that make up the service areas.

\section{Research methodology}

\subsection{Method statement}

The study area can be represented by a set of point objects (settlements) $\left\{P_{i}\right\}$ with a parameters set that characterize them. To simplify the calculations, we restrict the survey area (area of interest) to a rectangular section.

Building a graph model is based on assumptions (Davidich et al., 2020; Held, 2001; Krystopchuk, 2012; Sack and Urrutia, 1999):

- tops of the graph - settlements (represented as point objects), with coordinates determined after processing the map data $x_{i}, y_{i}$, and characteristic parameters $\psi_{i}$ (population, passenger trips distribution between settlements, number of routes passing through the settlement, etc.);

- edges of a graph are transport routes connecting settlements with each other;

- proximity zones (mutual influence zones) are built without taking into account the weight $v_{i}$ of vertices or the graph edges.

This approach involves three steps in the work execution:

- determination of the survey region and preparation of baseline data;

- building an irregular model;

- building a regular model.

In the first stage, we restrict the survey area to a rectangular section adjacent to the gravity center (regional or district center). At this stage, we prepare the initial data on the spatial location (determining the coordinates $x_{i}$ and $y_{i}$ ) of the point objects set (settlements) and their parameters $\psi_{i}$ - to be investigated.

The second stage is the construction of an irregular model. We build a graph model of transport links (settlements are vertices, transport routes are edges). The main parameters of the problem are the settlements' coordinates and thevalues of the parameter under study for the graph vertices.

The task of constructing proximity or interaction zones requires the determination of all points of the plane for which the distance to the objects of the set $\left\{P_{i}\right\}$ is minimal.

In the case when all the objects are point-like, this problem is defined as the task of constructing Voronoi diagrams (Held, 2001; Paul Chew, 1989; Sack and Urrutia,
1999; Thériault and Des Rosiers, 2013) - polygons formed by segments of perpendiculars drawn to the middle of the sides connecting the two nearest neighboring points.

The Delaunay triangulation and the Voronoi diagram are mutually ambivalent (Fig. 2).

For a given point $P_{i} \in\left\{P_{1}, \ldots, P_{N}\right\}$ on the plane, the Voronoi polygon is called the geometric location of points on the plane that are closer to $P_{i}$ than to any other given point $P_{i}, j \neq 1$ (Khitrov et al., 2019; Paul Chew, 1989; Thériault and Des Rosiers, 2013). Voronoi polygons set form a vector network.

The Voronoi diagram for a given set of points $\left\{P_{1}, \ldots, P_{N}\right\}$ is the sum of all Voronoi polygons of these points (Fig. 3(a)).

For some of the given points, the assigned Voronoi polygon will be infinite figures. Therefore, it is advisable to limit the whole area to a certain region - that is, to determine the area of interest. Let be the set of point objects and the interest area in the rectangle form (Fig. 3(a)). It is necessary to define all Voronoi polygons for given points (Fig. 3(e)).

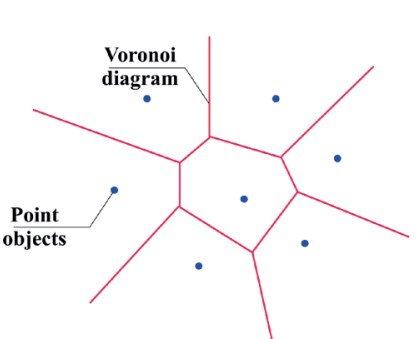

(a)

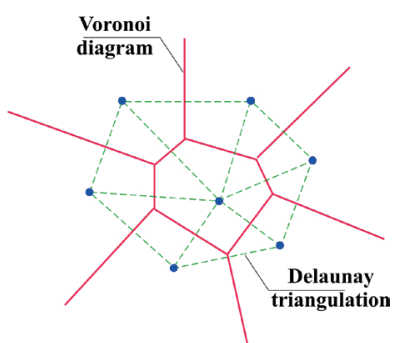

(b)
Fig. 2 The Voronoi diagram a) diagram example; b) dual to the diagram Delaunay triangulation

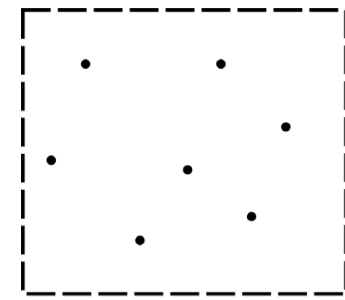

(a)

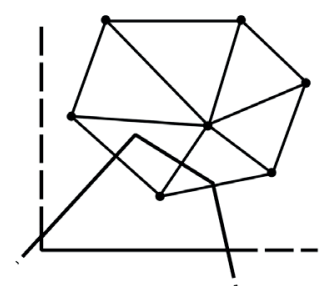

(d)

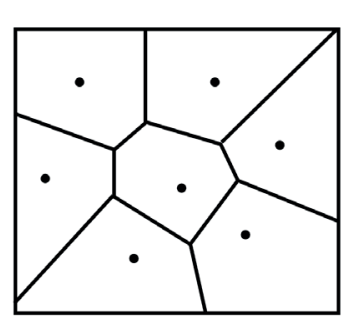

(e)
Fig. 3 Construction of the Voronoi diagram: a) source data and area of interest; b) Delaunay triangulation construction; c) Voronoi polygons construction for internal nodes; d) cutting off endless sides 
The Voronoi diagram algorithm provides the following steps:

Step 1. According to the initial data for the set of points, we construct the Delaunay triangulation (Fig. 3 (b)).

Step 2. For each triangle of triangulation, determine the center of the circle described in Eq. (1):

$x_{c}=b / 2 a$,

$y_{c}=(-c) / 2 a$,

$r^{2}=\left(b^{2}+c^{2}-4 a d\right) / 4 a^{2}$,

where $a, b, c, d$ are the determinants, calculated by the rules (Held, 2001; Paul Chew, 1989; Sack and Urrutia, 1999; Thériault and Des Rosiers, 2013).

Step 3. For each node we define the center of the Voronoi polygon. To do this, we go around the running node on adjacent triangles and collect the centers of the circles described. If the node is not at the boundary of the triangulation, then we take the coordinates of the assigned Voronoi polygon of this node (see Fig. 3(c)). If this node is at the boundary, then the Voronoi polygon is an infinite figure, in which case it is necessary to cut off its two infinite sides (Fig. 3(d)). The coordinates of the outer vertices (those that lie on the boundary of the rectangular region) are determined from the equation of the line: $(y=k x+b)$, which is the median perpendicular to one of the sides of the shell of the points set $y=a_{i j} x+b_{i j}$ and the fixed value of the coordinate $X$ (left or right border) or $Y$ (lower or upper bound). To find the coefficients $a_{i j}$ and $b_{i j}$ let us use the relations of Eq. (2):

$a_{i j}=\left(x_{j}-x_{i}\right) /\left(y_{i}-y_{j}\right)$,

$b_{i j}=\left(\left(y_{j}+y_{i}\right)-a_{i j}\left(x_{i}+x_{j}\right)\right) / 2$,

where $x_{i}, y_{i}, x_{j}, y_{j}$ are the coordinates of the two nodes for which the median perpendicular is constructed.

Then the parameter $\psi_{i}{ }^{\prime}$ for the $i$-th polygon is determined by the formula in Eq. (3):

$\psi_{i}^{\prime}=\psi_{i} / F_{i}$,

where $F_{i}$ is the polygon area to which the $i$-th vertex of the graph belongs.

The polygon area is determined by the coordinates of its vertices as in Eq. (4):

$$
\begin{aligned}
& F_{i}=0.5 \cdot\left|\sum_{i=1}^{k} x_{i} \cdot\left(y_{i+1}-y_{i-1}\right)\right| \\
& \text { at } y_{0}=y_{k}, y_{k+1}=y_{1} .
\end{aligned}
$$

At the third stage, we build a regular model. To move from an irregular to a regular model of the parameter under study, we perform the Delaunay triangulation (Held, 2001; Paul Chew, 1989; Sack and Urrutia, 1999; Thériault and Des Rosiers, 2013) and apply the inverse distance weighting method (Krystopchuk, 2012).

Proceeding from the main property - the Voronoi diagram to the Delaunay triangulation duality (Held, 2001; Sack and Urrutia, 1999), it is possible to construct the latter by connecting segments to those starting points for which the Voronoi polygons touch at least by angles (see Fig. 2(b)). Three types of objects are highlighted in triangulation: nodes (points, vertices), edges (segments), and triangles. One of the important operations performed in the triangulation construction is the check of the Delaunay condition for given triangles pairs. There are usually several verification methods:

1. check through the equation of the described circle;

2. check with the previously calculated circle described;

3. checking the opposite angles sum, etc. (Held, 2001; Paul Chew, 1989; Sack and Urrutia, 1999).

Currently, more than 30 Delaunay triangulation algorithms are known (Paul Chew, 1989; Sack and Urrutia, 1999) with different complexity of their execution. In our case, we use the convex strip merge algorithm. Its main idea is to split the initial points set into some stripes, and use a fast algorithm for constructing convex triangulation of a strip of points.

One of the most important parameters of band triangulation algorithms is the number of bands. For this purpose it is proposed to minimize the average total length of the edges of all triangulations obtained. Let us make the following assumptions:

1. The coordinates of the points are distributed in a rectangular area of width $a$ and height $b$ uniformly and independently by $X$ and $Y$.

2. The distance between the points will be determined by Manhattan (Paul Chew, 1989; Sack and Urrutia, 1999).

Once the triangulation is complete, the set of settlements and transport links forms an irregular network.

\subsection{The method of shift from irregular to regular resettlement model}

In order to move from an irregular resettlement network to a regular one, it is necessary to construct a regular grid for the parameter under study with a sufficiently small cell size 
(square grid), which is necessary for mapping this parameter. For this purpose we build a secondary regular square grid with a side of $1 \mathrm{~km}$. We find the function's value of the investigated parameter in each node of this grid. The problem is solved by the inverse distance weighting method. The function of the parameter under study by this method takes the form (Eq. (5)):

$\psi(x, y)=\left(\psi_{1}^{\prime} w_{1}+\psi_{2}^{\prime} w_{2}+\psi_{3}^{\prime} w_{3}\right) /\left(w_{1}+w_{2}+w_{3}\right)$,

where $\psi_{1}^{\prime}, \psi_{2}^{\prime}, \psi_{3}^{\prime}$ are the average value of the parameter under study (defined in the previous step) at the triangle points (vertices) to which the running point belongs; $w_{1}$, $w_{2}, w_{3}$ - weights determined by the ratio (Eq. (6)):

$w_{1}=1 / l_{i}^{2}$,

where $l_{i}$ is the distance from the assigned triangle vertices to the running node of the secondary grid (Fig. 4); $(x, y)$ the node coordinates.

As a result of the operations done, we obtain a tabulated function of the parameter under study for the region and visualize the calculated parameters in the form of graphical dependencies or in the three-dimensional surface form.

\section{Results}

\subsection{Testing the hypothesis of exponential population density distribution in the study area}

Exploring the resettlement patterns indicate a significant uneven distribution of population across the region. It is therefore advisable to divide the territory into more functionally homogeneous areas (Fig. 5). In this case, we

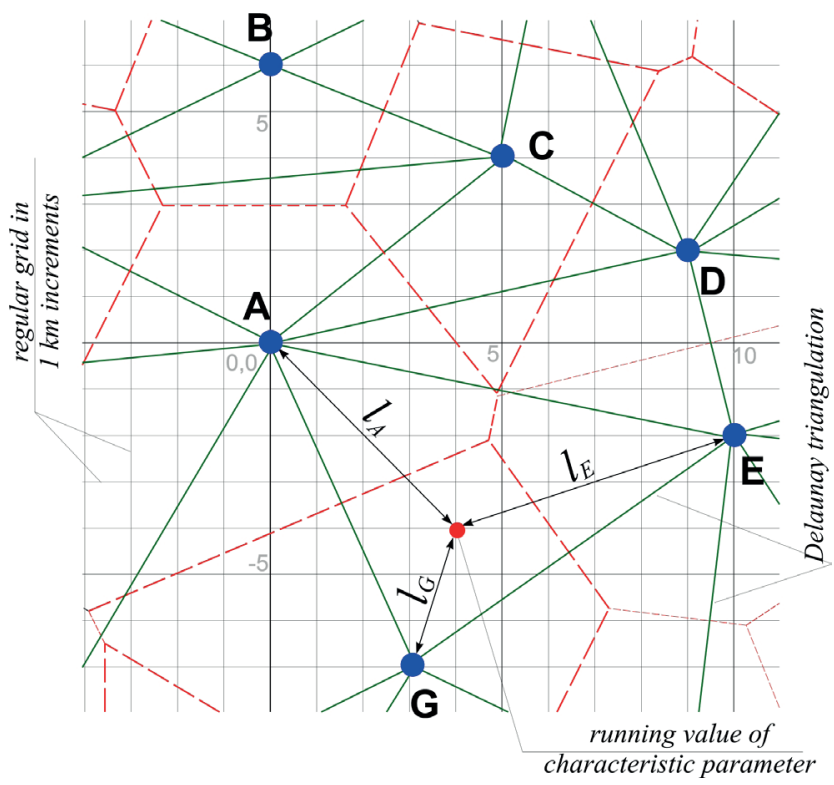

Fig. 4 Transition from irregular to regular model

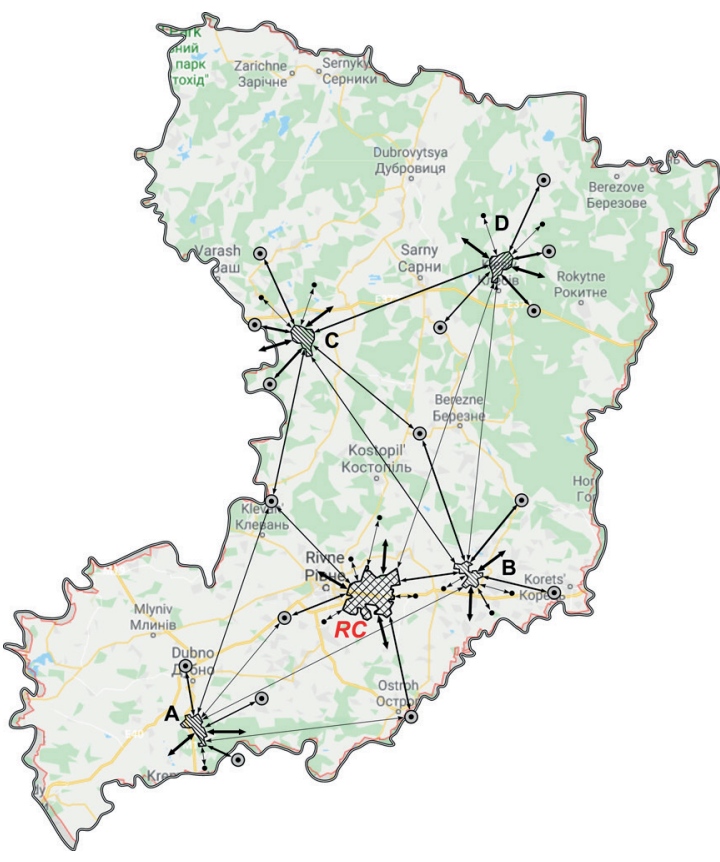

Fig. 5 -dimensional spatial orientation scheme of rural and suburban population connections (on the example of Rivne region): $\mathrm{RC}$ regional center, A - D - territories of the united communities near the subsystems centers $S_{2}-S_{4}$ and on the periphery, respectively

introduce the notion of hierarchy of territorial subsystems (Burko et al., 2020; Khitrov et al., 2019; Krystopchuk, 2012), within which the average maximum service radius $\bar{R}_{i \max }$ of rural (suburban) territories and their centers connected to the values given in Table 1 .

As a unit of measure, a settlement with a population of 1000 inhabitants is accepted. The statistics data in quantity $n=478$ are grouped by intervals in Table 2 .

Table 1 Average maximum service radii for rural and suburban areas and their centers within hierarchical territorial systems

\begin{tabular}{lccccc}
\hline Rank of the subsystem & $\mathrm{S}_{5}$ & $\mathrm{~S}_{4}$ & $\mathrm{~S}_{3}$ & $\mathrm{~S}_{2}$ & $\mathrm{~S}_{1}$ \\
\hline $\bar{R}_{i \max }, \mathrm{km}$ & 4.4 & 13.9 & 25.6 & 64.5 & 180 \\
\hline
\end{tabular}

Table 2 Statistical processing of data on the number of inhabitants by settlements within $50 \mathrm{~km}$ from the regional center (Rivne) (Emp. - empirical, Theo. - theoretical)

\begin{tabular}{cccccccc}
\hline & & & & \multicolumn{2}{c}{ Frequency } & Frequency & \multicolumn{2}{c}{$\begin{array}{c}\text { Distribution } \\
\text { function }\end{array}$} \\
& & $m_{N}$ & $r_{N}$ & Emp. & Theo. & Emp. & Theo. \\
\hline 0 & 0.5 & 299 & 0.6255 & 1.251 & 1.150 & 0.625 & 0.575 \\
0.5 & 1.0 & 117 & 0.2447 & 0.489 & 0.466 & 0.870 & 0.808 \\
1.0 & 1.5 & 34 & 0.0711 & 0.142 & 0.188 & 0.941 & 0.902 \\
1.5 & 2.0 & 15 & 0.0313 & 0.062 & 0.076 & 0.972 & 0.940 \\
2.0 & 2.5 & 7 & 0.0146 & 0.029 & 0.031 & 0.987 & 0.956 \\
2.5 & 3.0 & 4 & 0.0083 & 0.016 & 0.012 & 0.995 & 0.962 \\
3.0 & 3.5 & 2 & 0.0041 & 0.008 & 0.005 & 1.000 & 0.965 \\
\hline
\end{tabular}


In order to establish resettlement patterns and to determine population density in the study area, let us consider the hypothesis that the population of the settlements in a certain area, which is limited by the distance from the regional center to $50 \mathrm{~km}$ (area of organization and activity of suburban routes) is subject to description by indicator (exponential) distribution patterns. We find the density and the function of a random variable (de Dios Ortúzar and Willumsen, 2011; Yi et al., 2010).

The statistical processing results of the population's distribution by settlements are given in Table 3 .

Histograms of population distribution by settlements and theoretical density of distribution probability are shown in Figs. 6 to 8.

The consistency of theoretical and statistical distribution is checked according to Pearson $\left(\chi^{2}\right)$ and Kolmogorov criteria. To do this, we determine the magnitude of the discrepancy (de Dios Ortúzar and Willumsen, 2011; Yi et al., 2010). The calculations showed that the obtained values are not random because the statistical distribution of trips correlates with the theoretical at .

Thus, as a result of processing statistical data on the number of residents in settlements located in the study territory, it is established that the hypothesis of their distribution by exponential distribution is confirmed with a probability of consistency of more than 0.25 . The mathematical expectation of the inhabitants number in settlements ranges from 500 to 550 inhabitants, on the basis of which in determining the potential of services such a settlement can be taken as the average.

\subsection{Research results and regular model of population density function}

In determining the parameters, it is advisable to use an approach based on the study of interaction patterns

Table 3 Results of statistical analysis of population distribution in settlements

\begin{tabular}{|c|c|c|c|}
\hline \multirow{2}{*}{ Parameter name } & \multicolumn{3}{|c|}{ Area of population's distribution study } \\
\hline & $0-50 \mathrm{~km}$ & $0-35 \mathrm{~km}$ & $35-50 \mathrm{~km}$ \\
\hline Area of study area, $\mathrm{km}^{2}$ & 7850 & 3850 & 4000 \\
\hline Number of settlements & 478 & 214 & 264 \\
\hline $\begin{array}{l}\text { Mathematical expectation } \\
M[T]\end{array}$ & 0.528 & 0.553 & 0.500 \\
\hline $\begin{array}{l}\text { Theoretical probability } \\
\text { density } f(t)\end{array}$ & $1.894 e^{-1.894 t}$ & $1.807 e^{-1.807 t}$ & $2 e^{-2 t}$ \\
\hline Parameters $\chi^{2} / r$ & $2.78 / 5$ & $6.58 / 5$ & $2.28 / 5$ \\
\hline $\begin{array}{l}\text { Probability of consistency } \\
\text { by criterion } \chi^{2}\end{array}$ & 0.734 & 0.253 & 0.808 \\
\hline
\end{tabular}

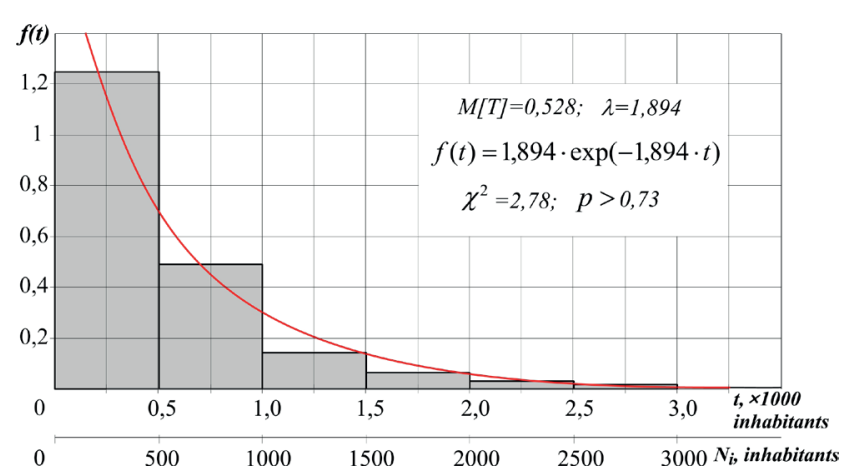

Fig. 6 Histogram and density of probability of population distribution by settlements (study area $0-50 \mathrm{~km}$ )

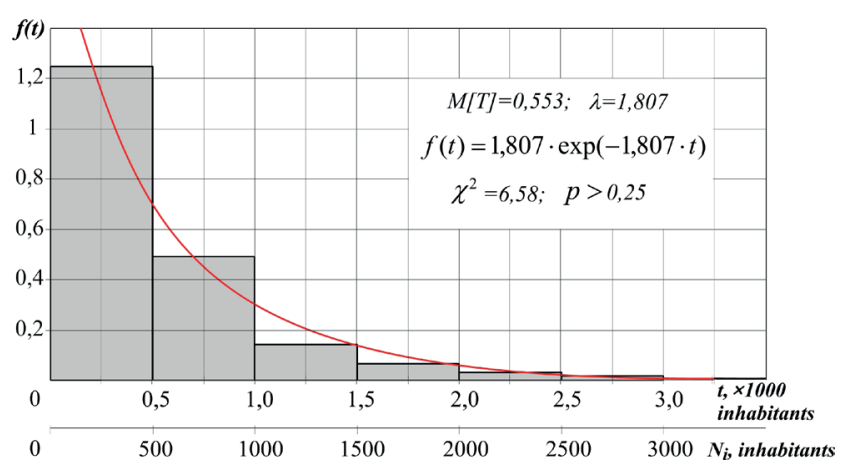

Fig. 7 Histogram and density of probability of population distribution by settlements (study area $0-35 \mathrm{~km}$ )

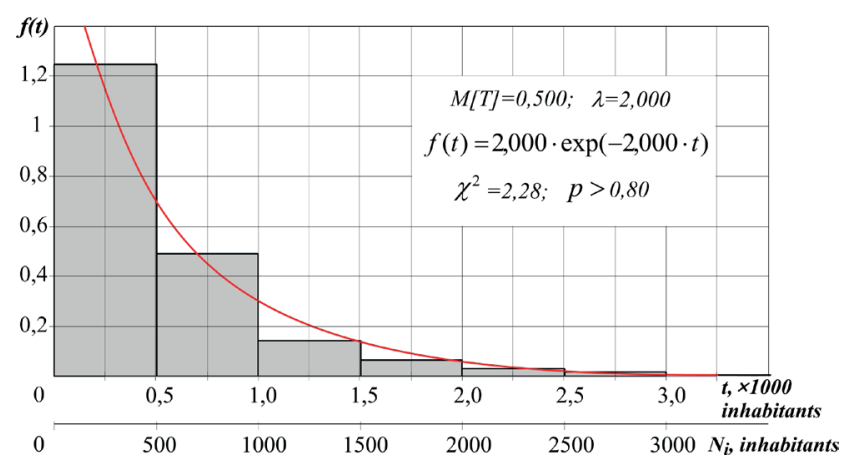

Fig. 8 Histogram and density of probability of population distribution by settlements (study area $35-50 \mathrm{~km}$ )

between the population, production with traffic flows. The main task is to establish the feedback type of objects located in space, that is, settlements, on mobility in transport services: planning the network, its capacity, studying the patterns of settlement and spatial self-organization of the population. For comprehensive studies of the patterns of changes in the density of transport links in the passenger transport system, it is proposed to use an approach based on the GIS technologies application (Kapski et al, 2019), it allows to obtain tabulated functions of indicators: 
- population density of the defined region;

- the carrying capacity of the itinerary network and its individual sections;

- transport mobility of the population etc.

To determine the resettlement patterns in the region around the gravity center (regional, district centers), a regular model for the population density function was constructed, depending on the distance to the gravity center $h_{F}(x, y)$. The construction of a regular model was carried out with the implementation of the construction steps described in Subsections 3.1. and 3.2. Simultaneously, for the selected region the survey was conducted:

1. Determining the survey region. We restrict the survey region to a rectangular section adjacent to the regional center (Rivne). At this stage, we prepare the initial data on the spatial location (determining the coordinates $x_{i}$ and $y_{i}$ ) of the point objects set (settlements) and population $h_{F i}$.

2. The construction of an irregular model is a graph model of transport links (settlements are vertices, transport paths are edges). The main parameters of the problem are the coordinates of settlements and the number of inhabitants.

The first step in constructing the population density function is to determine the population density for the major settlements in the region. Let us suppose that the population is concentrated in a settlement represented by a point object. To determine the mutual influence zones of settlements (polygons), the Voronoi diagram was constructed. The fragment of the diagram for our task is given in Fig. 9.

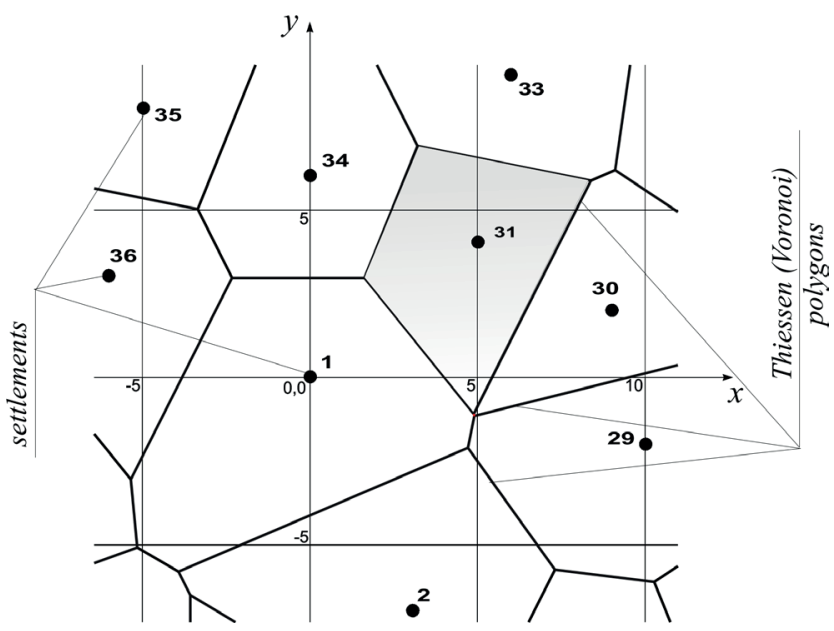

Fig. 9 A fragment of the Voronoi diagram for studying the population density of a region
Population density for the -th polygon is determined by Eq. (7):

$h_{F i}=H_{F i} / F_{i}$,

where $F_{i}$ is the area of the polygon to which the settlement belongs.

3. Building a regular model. For the transition from the irregular to the regular population density model, we perform the Delaunay triangulation and apply the inverse distance weighting method. A fragment of the Delaunay triangulation for the task of the study is shown in Fig. 10. We define the population density in the $i$-th settlement as the average value for the $i$-th polygon by Eq. (7). The population of settlements forms an irregular network. The problem of constructing a regular network for the population density function is solved by the inverse distance weighting method. Population density function of the region by the inverse distance weighting method looks as in Eq. (8):

$h_{F}(x, y)=\left(h_{F 1} w_{1}+h_{F 2} w_{2}+h_{F 3} w_{3}\right) /\left(w_{1}+w_{2}+w_{3}\right)$,

where $h_{F 1}, h_{F 2}, h_{F 3}$ are the population density (determined at the previous stage) at points (vertices) of the triangle to which the running point belongs; $w_{1}, w_{2}, w_{3}$ are the weights determined by the ratio (Eq. (6)).

As a result of the implementation of the mentioned steps for constructing a regular model of the population density function, we obtained a tabulated population density

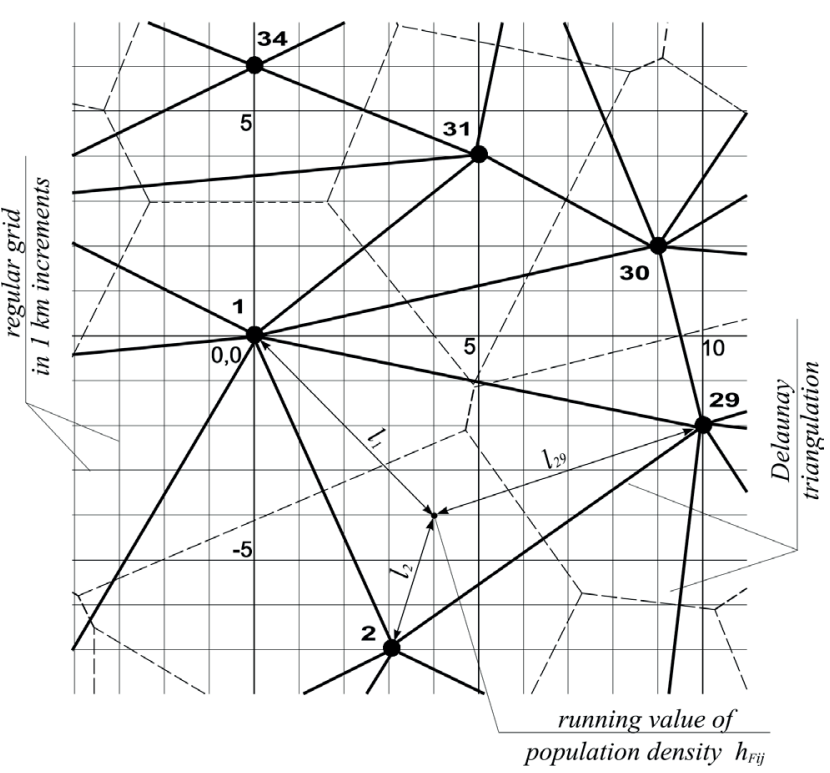

Fig. 10 A fragment of the Delaunay triangulation and construction of a regular population density function for the study region 
function for the considered Rivne region. A graphical representation of the function is shown in Figs. 11 and 12. In the calculations, the settlements' characteristics were used according to the statistics of the census, the coordinates of the points were determined by the processing of cartographic objects.

The use of the STATISTICA 6.0 statistical processing package allows to build a Voronoi diagram for multiple points based on the source data, which is the coordinates of the points.

The results are processed and visualized using an Excel spreadsheet and SURFER 6.0.

\subsection{Model calibration to calculate demand for} transport services when investigating the functioning of the suburban passenger transport system

The determining factors in forming the size of the transport area of the route (de Dios Ortúzar and Willumsen, 2011; Khitrov et al., 2019) are the route length $L_{r}$ and the population density in the study area. At the stage of designing a new route network or investigating the functioning of an existing one, it is necessary to have information on the patterns of population distribution across the territory. Studies of these patterns indicate a significant uneven population

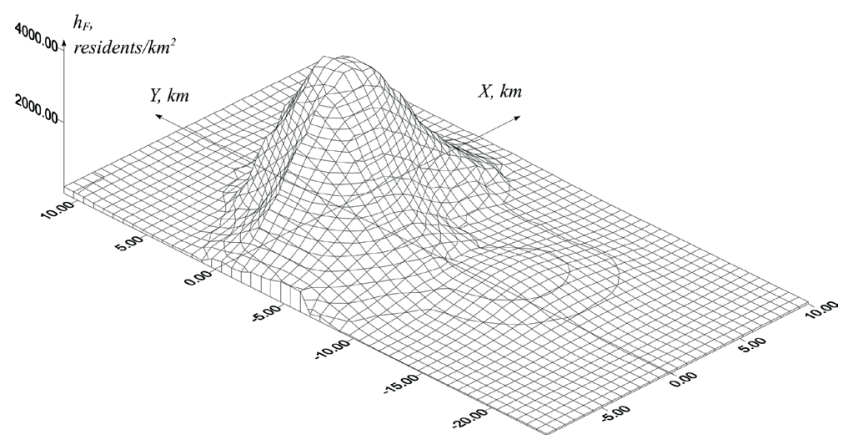

Fig. 11 Graphic representation of the population density function for the Rivne region in the immediate vicinity of the regional center

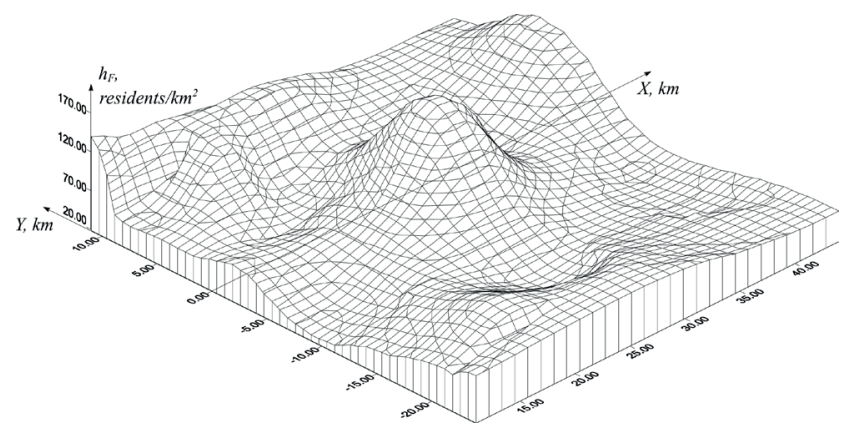

Fig. 12 Graphic representation of the population density function for the Rivne region at a distance of $10-45 \mathrm{~km}$ from the regional center

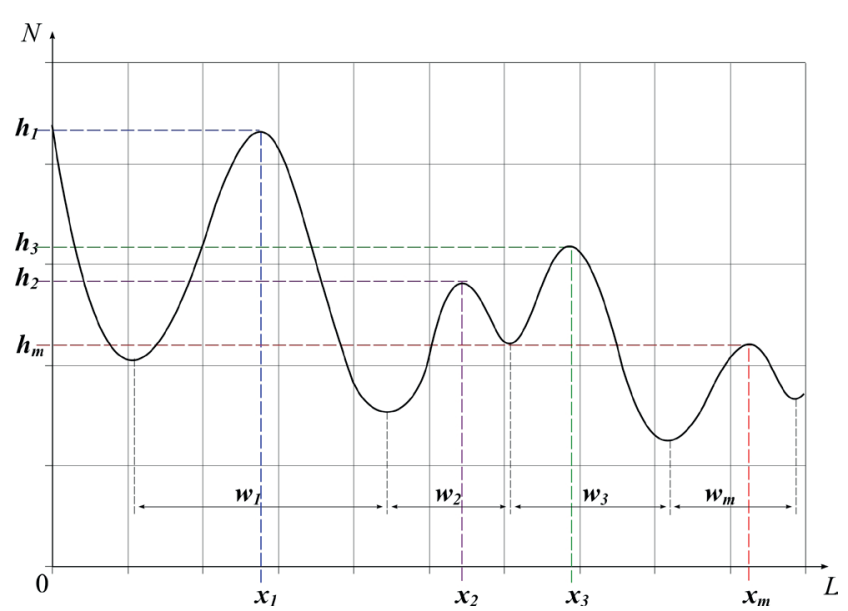

Fig. 13 Graph of population density by territory depending on the location of settlements along the route relative to a certain center

distribution, depending on the location of settlements relative to a certain center, it has the form shown in Fig. 13, and is described by the function as Eq. (9):

$h_{f}(x)=0.5 \cdot \sum_{i=1}^{k} h_{i} \cdot b_{i} \cdot e^{-\left|\left(x-l_{i}\right) / w_{i}\right|}$,

where $k$ is the number of settlements on the route; $h_{i}$ is the population density in the $i$-th settlement; $b_{i}$ is the coefficient taking into account the $i$-th section coverage of the route of communication; $l_{i}$ is the remoteness of a settlement from a certain center; $w_{i}$ is a calibration factor that determines the width of the impact of a settlement; $x$ is the coordinate that determines population density.

The use of function (Eq. (9)) must satisfy the condition of population normalization in settlements located in the route Eq. (10):

$\int_{l_{\min }}^{l_{\max }} h_{f}(x) d x=N$

where $N$ is the total number of inhabitants in the area covered by transport services; $l_{\min }$ is the minimum distance of the settlement from a regional or district center; $l_{\max }$ is the maximum distance of the settlement from the regional or district center, for suburban communication, $l_{\max }=50 \mathrm{~km}$.

In turn, $N=\sum_{i=1}^{m} N_{i}$, where $m$ is the number of settlements covered by transport services; $N_{i}$ is the number of residents in the $i$-th settlement, located on the route.

As a result of integration (Eq. (9)) we have Eq. (11):

$\int_{l_{\text {min }}}^{l_{\text {max }}} h_{f}(x) d x=0.5 \cdot\left[\left(C_{i 1} / e^{A_{1} \cdot \operatorname{sign}\left(A_{1}\right)}\right)-\left(C_{i 2} / e^{A_{2} \cdot \operatorname{sign}\left(A_{2}\right)}\right)\right]$

where: 


$$
\begin{aligned}
& C_{i 1}=\sum_{i} h_{i} \cdot b_{i} \cdot w_{i} / \operatorname{sign}\left(\left(l_{i}-l_{\text {max }}\right) / w_{i}\right), \\
& C_{i 2}=\sum_{i} h_{i} \cdot b_{i} \cdot w_{i} / \operatorname{sign}\left(\left(l_{i}-l_{\text {min }}\right) / w_{i}\right), \\
& A_{1}=\left(l_{i}-l_{\max }\right) / w_{i} ; A_{2}=\left(l_{i}-l_{\text {min }}\right) / w_{i} .
\end{aligned}
$$

The parameter $w_{i}$ is determined from the normalization condition (Eq. (12)):

$w_{i}=\left(l_{\max }-l_{i}\right) / W(Z)$,

where $Z=0.5 \cdot\left(\left(l_{i}-l_{\max }\right) \cdot \sum_{i}\left(h_{i} \cdot b_{i}\right)\right) / N ; W(Z)$ is the Lambert function, defined as the inverse function to $f(W)=W \cdot \exp (W)$, for any $Z: Z=W(Z) \cdot \exp (W(Z))$.

By differentiating the implicit function (de Dios Ortúzar and Willumsen, 2011; Yi et al., 2010), we obtain that at $Z \neq-(1 / e)$ :

$$
d W / d Z=W(Z) /(Z \cdot(1+W(Z)) .
$$

Thus, the population density in the study area can be determined by building a regular model or described by a theoretical function (Eq. (9)).

\subsection{Comparative analysis of results}

The results of the population density calculations along the routes of suburban p routes for a particular region in different directions by the Regular Resettlement Model (RRM) and Theoretical Resettlement Model (TRM) can be tabulated. Moreover, the calibration coefficient that determines the width of the impact of the $i$-th settlement can be found as the ratio of the inhabitants number in this settlement to the number of inhabitants of the average settlement (in our case, 500 inhabitants).

Table 4 shows the comparative analysis results of regular and theoretical models of resettlement. The correlation level is $0.959-0.976$, which indicates a close connection between population density and distance from the gravity center. Testing the results by Fisher and Student's criteria showed that the probability of agreement of the results obtained by the regular and theoretical model of the resettlement described by function (Eq. (9)) is in the range 0.21-0.47.

Graphical dependencies constructed using an exponential resettlement distribution (de Dios Ortúzar and Willumsen, 2011), with parameters $b=1 / l_{a v}$, where $l_{a v}$ is the average passenger travel distance in the chosen direction of communication, and $t=l$ is the complexity of the center connection, expressed in units of the distance of the connection, and the theoretical resettlement model (Eq. (9)) are shown in Figs. 14 to 17.

Graphical dependencies analysis (see Figs. 14 to 17) allows us to conclude that the use of a theoretical settlement model provides greater accuracy in modeling passenger flows and the potential of transport services in suburban traffic, which is associated with a very significant uneven distribution of the population along the suburban traffic route. However, determining the calibration coefficients of the mutual influence of settlements as a function of the theoretical model of resettlement in each case for different regions requires a study of resettlement in the territory.

With a clear identification of the gravity center, as an administrative-territorial unit, which is decisive in the passenger flows generation from the surrounding territories and settlements, which are very different in size, area, size of the zone of mutual influence; construction of a regular resettlement model allows to assess the potential of transport services at designated area. The use of computational geometry methods makes it possible to more closely match the demand for transport services with the offer of such services. In turn, it is possible to achieve efficient use

\begin{tabular}{|c|c|c|c|c|c|c|c|c|}
\hline \multirow{2}{*}{ Statistical parameter } & \multicolumn{2}{|c|}{ East direction } & \multicolumn{2}{|c|}{ North direction } & \multicolumn{2}{|c|}{ South direction } & \multicolumn{2}{|c|}{ West direction } \\
\hline & RRM & TRM & RRM & TRM & RRM & TRM & RRM & TRM \\
\hline Average value & 90.36 & 90.46 & 83.00 & 84.42 & 65.50 & 65.32 & 82.37 & 81.15 \\
\hline Dispersion & 1548 & 1422 & 1803 & 1698 & 1380 & 1413 & 4247 & 3666 \\
\hline The correlation level & 0.976 & 0.959 & 0.976 & 0.968 & & & & \\
\hline Average approximation error, $\%$ & 7.82 & 8.97 & 8.90 & 9.85 & & & & \\
\hline$F$ - Fisher's criterion, $\left(F^{c r i t}=1.641\right)$ & 1.088 & 1.061 & 0.977 & 1.158 & & & & \\
\hline Probability of agreement, $p$ & 0.39 & 0.42 & 0.47 & 0.31 & & & & \\
\hline Student's t-test, $\left(t^{\text {crit }}=1.679\right)$ & -0.082 & -0.797 & 0.146 & 0.495 & & & & \\
\hline Probability of agreement, $p$ & 0.47 & 0.21 & 0.44 & 0.31 & & & & \\
\hline
\end{tabular}
of vehicles, transport infrastructure, taking into account the real needs of the population of a certain region.

Table 4 Results of the comparative analysis of the Regular Resettlement Model (RRM) and the Theoretical Resettlement Model (TRM) 


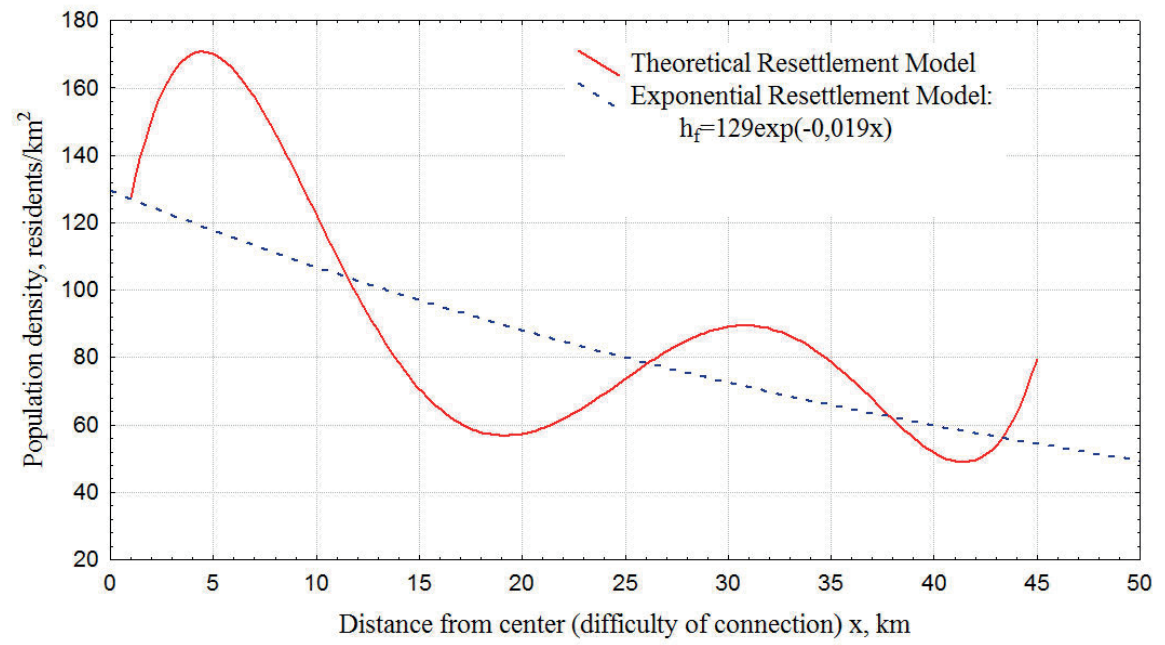

Fig. 14 Graphical dependences of population density on Rivne region routes by theoretical and exponential resettlement distribution according to Eastern directions of routes

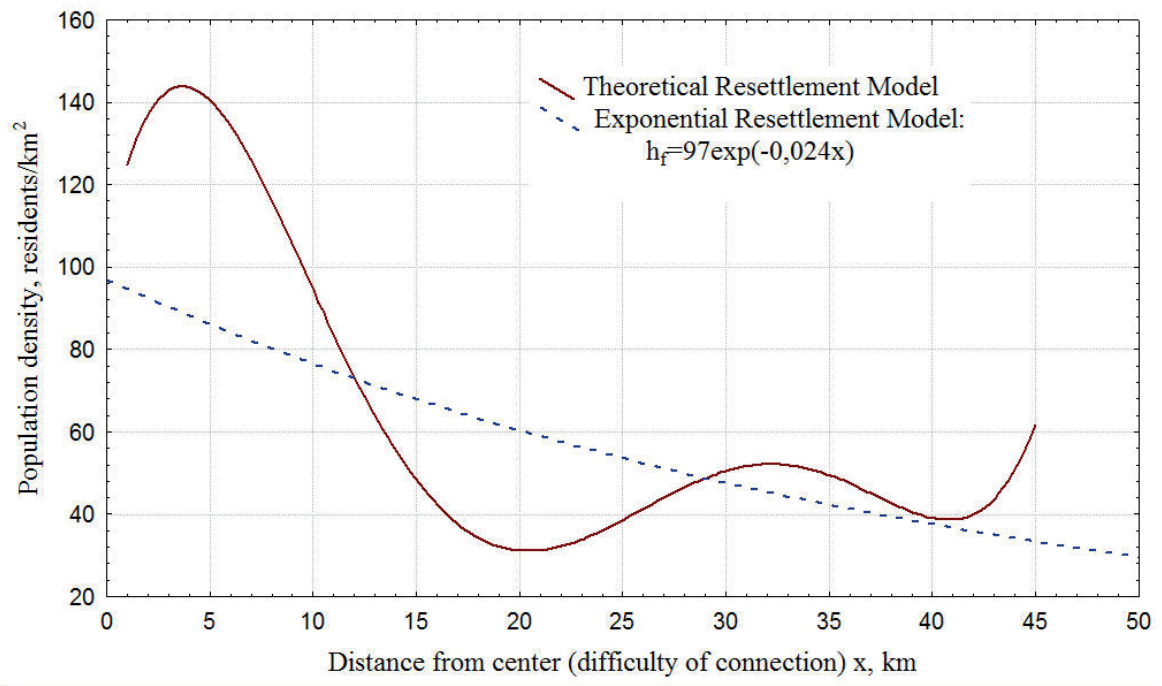

Fig. 15 Graphical dependences of population density on Rivne region routes by theoretical and exponential resettlement distribution according to Southern directions of routes

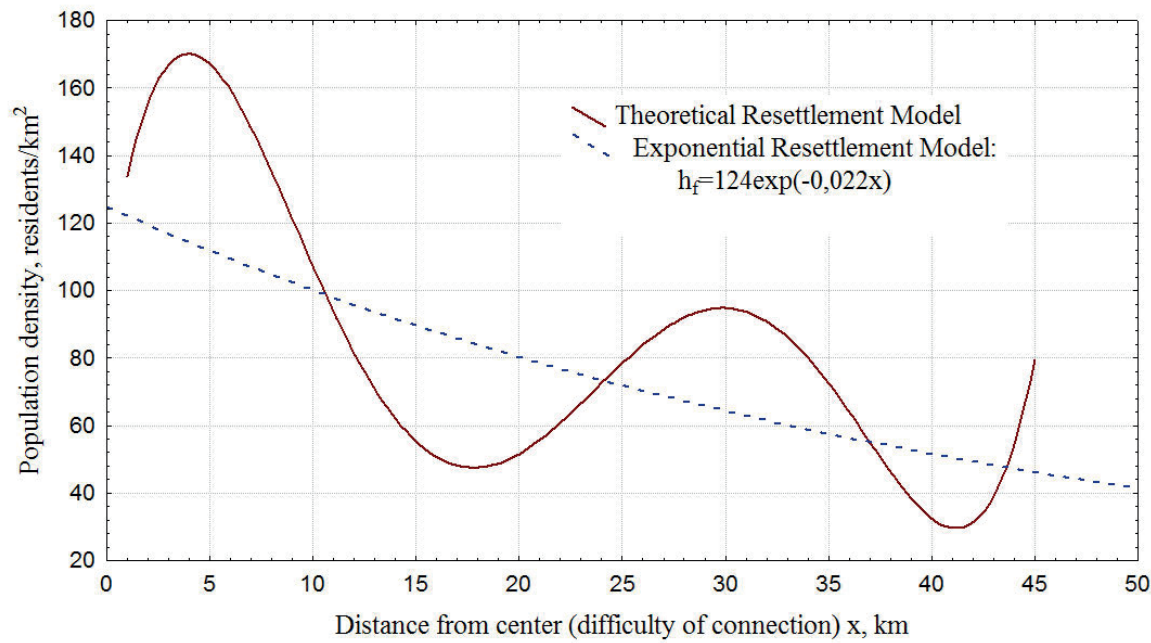

Fig. 16 Graphical dependences of population density on Rivne region routes by theoretical and exponential resettlement distribution according to Northern directions of routes 


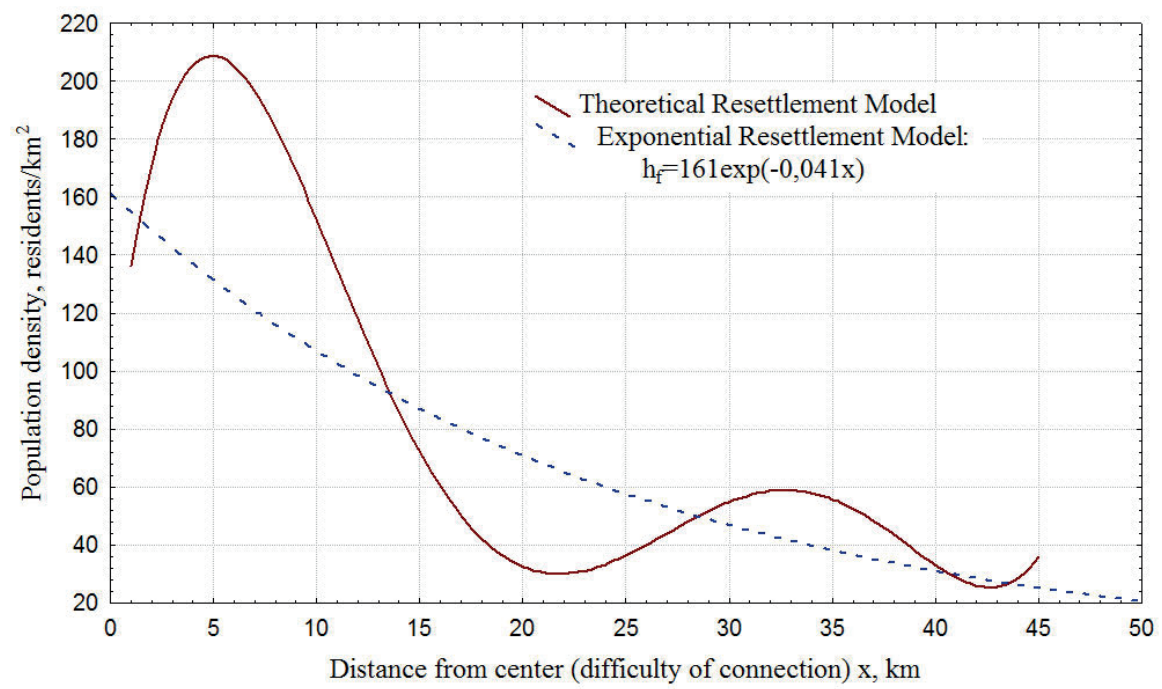

Fig. 17 Graphical dependences of population density on Rivne region routes by theoretical and exponential resettlement distribution according to Western directions of routes

\section{Conclusions}

Population transit from origin to destination can be divided into foot traffic (from origin to transport and from transport to destination) and transportation. The volumes and directions of passengers flows depend both on the needs of resident's location and trip's characteristics. Moreover, the amounts of pedestrian flows are irregular during the day. For rural and suburban areas, it depends on the public transport schedule.

Known methods (Abdel-Aal, 2014; Cordera et al., 2018; Vakulenko et al., 2019) of establishing the transport services' potential and forming passenger trips matrices are based on the use of gravity models, and have been developed, mainly for the study of interaction between transport areas of cities. However, for the trips generation in the suburban traffic, with the interaction of many settlements with different population densities and remoteness from the city center, the use of gravity models is difficult. Unlike the existing methods presented in (Cremer and Keller, 1987; de Dios Ortúzar and Willumsen, 2011; Kujala et al., 2018; Thériault and Des Rosiers, 2013) of establishing the resettlement patterns, the proposed method is easier to use in practice and it gives fairly accurate results.

The population chooses the gravity center, taking into account the constraints imposed by the transportation system and based on subjective considerations of the service quality. The distribution of rural and suburban residents' displacement into cities is influenced by the size of the city, the range of displacement, the purpose of displacement. The distribution of transport links determines the scattering field of the starting and ending points of displacements. Since the density of their dispersion in relation to the settlements is the same, on their set we distinguish the territorial units that make up the service areas.

The study of the patterns of settlement indicates a significant uneven distribution of population across the region, so it is advisable to divide the territory into more homogeneously functional areas. An approach based on the application of GIS-technologies was used to establish the resettlement patterns of suburban area residents and to obtain a tabulated population density function of a particular region.

The type of theoretical function of population density and the calibration coefficients determined by the ratio of the number of inhabitants in the settlement and the number of inhabitants of the average settlement equal to 500 inhabitants are established. The theoretical function has made it possible to more accurately determine the potential of suburban transport services compared to the known models (de Dios Ortúzar and Willumsen, 2011), which is due to the significant unevenness of population density along routes. Satisfactory results were obtained in the process of modeling passenger traffic on the route network of suburban passenger traffic of Rivne region, which made it possible to adapt the transport services' offer to the real needs of the population. 


\section{References}

Abdel-Aal, M. M. M. (2014) "Calibrating a trip distribution gravity model stratified by the trip purposes for the city of Alexandria", Alexandria Engineering Journal, 53(3), pp. 677-689. https://doi.org/10.1016/j.aej.2014.04.006

Almetova, Z. V., Shepelev, V. D., Kuznetsov, N. A. (2019) "The Integrative Process of Transport Systems of the Eurasian Economic Union", IOP Conference Series: Earth and Environmental Science, 272(2), Article Number: 022234.

https://doi.org/10.1088/1755-1315/272/2/022234

Amavi, A. A., Romero, J. P., Dominguez, A., dell'Olio, L., Ibeas, A. (2014) "Advanced Trip Generation/Attraction Models", Procedia Social and Behavioral Sciences, 160, pp. 430-439. https://doi.org/10.1016/j.sbspro.2014.12.155

Burko, D., Lobashov, O., Prasolenko, O., Gyulyev, N., Kumar, C. (2020). "Establishing Patterns of the Urban Transport Flows Functioning On Urban Network Parameters", Transportation Research Procedia, 48, pp. 793-800. https://doi.org/10.1016/j.trpro.2020.08.082

Cordera, R., Sañudo, R., dell'Olio, L., Ibeas, Á. (2018) "Trip distribution model for regional railway services considering spatial effects between stations", Transport Policy, 67, pp. 77-84. https://doi.org/10.1016/j.tranpol.2018.01.016

Cremer, M., Keller, H. (1987) "A new class of dynamic methods for the identification of origin-destination flows", Transportation Research Part B: Methodological, 21(2), pp. 117-132. https://doi.org/10.1016/0191-2615(87)90011-7

Davidich, N., Galkin, A., Sabadash, V., Chumachenko, I., Melenchuk, T., Davidich, Y. (2020) "Projecting of Urban Transport Infrastructure Considering the Human Factor", Communications - Scientific letters of the University of Zilina, 22(1), pp. 84-94. https://doi.org/10.26552/com.C.2020.1.84-94

de Dios Ortúzar, J., Willumsen, L. G. (2011) "Modelling Transport", John Wiley \& Sons, Chichester, UK.

Galkin, A., Lobashov, O., Capayova, S., Hodakova, D., Schlosser, T. (2018) "Perspective of Decreasing of Road Traffic Pollution in the Cities", In: 18th International Multidisciplinary Scientific GeoConference SGEM 2018, Albena, Bulgaria, pp. 547-554. https://doi.org/10.5593/sgem2018/4.2/s19.071

Galkin, A., Davidich, Y., Kush, Y., Davidich, N., Tkachenko I. (2019) "Improving of Urban Public Transportation Quality via Operator Schedule Optimization", Journal of Urban and Environmental Engineering, 13(1), pp. 23-33. https://doi.org/10.4090/juee.2019.v13n1.023033

Held, M. (2001) "VRONI: An engineering approach to the reliable and efficient computation of Voronoi diagrams of points and line segments", Computational Geometry, 18(2), pp. 95-123. https://doi.org/10.1016/S0925-7721(01)00003-7

Kapski, D., Kasyanik, V., Lobashov, O., Volynets, A., Kaptsevich, O., Galkin, A. (2019) "Estimating the Parameters of Traffic Flows on the Basis of Processing of Localization Data on the Movement of Vehicles", Communications - Scientific Letters of the University of Zilina, 21(2), pp. 89-99.

https://doi.org/10.26552/com.C.2019.2.89-99
Khitrov, I., Soroka, V., Krystopchuk, M., Pashkevych, S. (2019). "Модель формування площі транспортного обслуговування маршрутів пасажирського сполучення" (Model forming area of transport service routes of passenger traffic), Modern Technologies in Mechanical Engineering and Transport, 2(13), pp. 173-184. (in Ukrainian) https://doi.org/10.36910/automash.v2i13.101

Krystopchuk, M. Ye. (2012) "Соціально-економічна ефективність пасажирської транспортної системи приміського сполучення"(Social and economic efficiency of passenger transportation system suburban communication), Monograph, National University of Water and Environmental Engineering, Rivne, Ukraine (in Ukrainian) [online] Available at: http://ep3.nuwm.edu. ua/1645 [Accessed: 10 Nov 2019]

Kujala, R., Weckström, C., Mladenović, M. N., Saramäki, J. (2018) "Travel times and transfers in public transport: Comprehensive accessibility analysis based on Pareto-optimal journeys", Computers, Environment and Urban Systems, 67, pp. 41-54. https://doi.org/10.1016/j.compenvurbsys.2017.08.012

Makarova, I., Pashkevich, A., Shubenkova, K. (2017) "Ensuring Sustainability of Public Transport System through Rational Management", Procedia Engineering, 178, pp. 137-146. https://doi.org/10.1016/j.proeng.2017.01.078

Oliveira, H. F., Gonçalves, M. B., Cursi, E. S., Novaes, A. G. (2011) "Development of a Computational System to Determine the Optimal Bus-stop Spacing in order to Minimize the Travel Time of All Passengers", In: Kreowski, H. J., Scholz-Reiter, B., Thoben, K. D. (eds.) Dynamics in Logistics, Proceedings, Springer-Verlag, Berlin, Germany, pp. 15-25. https://doi.org/10.1007/978-3-642-11996-5_2

Paul Chew, L. (1989) "Constrained delaunay triangulations", Algorithmica, 4(1-4), pp. 97-108. https://doi.org/10.1007/BF01553881

Pucher, J., Renne, J. L. (2005) "Rural mobility and mode choice: Evidence from the 2001 National Household Travel Survey", Transportation, 32(2), pp. 165-186. https://doi.org/10.1007/s11116-004-5508-3

Sack, J. R., Urrutia, J. (1999) "Handbook of Computational Geometry", North Holland, Amsterdam, Netherlands.

Saka, A. A. (2001) "Model for Determining Optimum Bus-Stop Spacing in Urban Areas", Journal of Transportation Engineering, 127(3), pp. 195-199. https://doi.org/10.1061/(ASCE)0733-947X(2001)127:3(195)

Schlosser, T., Schlosser, P., Hodakova, D., Zuzulova, A., Capayova, S. (2019) "Modelling of Capacity and Public Transport Modal Split for New City Centre in Bratislava", IOP Conference Series: Materials Science and Engineering, 603(5), Article Number: 052029. https://doi.org/10.1088/1757-899x/603/5/052029

Stepanchuk, O., Bieliatynskyi, A., Pylypenko, O., Stepanchuk, S. (2016) "Peculiarities of City Street-Road Network Modelling", Procedia Engineering, 134, pp. 276-283. https://doi.org/10.1016/j.proeng.2016.01.008

Thériault, M., Des Rosiers, F. (2013) "Modeling Urban Dynamics: Mobility, Accessibility and Real Estate Value", John Wiley \& Sons, Hoboken, NJ, USA. 
Tkhoruk, Y., Kucher, O., Holotiuk, M., Krystopchuk, M., Tson, O., Olejarz, T. (2019) "Modeling of assessment of reliability transport systems", In: ICCPT 2019: Current Problems of Transport: Proceedings of the 1st International Scientific Conference, Ternopil, Ukraine, pp. 204-210.

https://doi.org/10.5281/zenodo.3387556
Vakulenko, K., Kuhtin, K., Afanasieva, I., Galkin, A. (2019) "Designing Optimal Public Bus Route Networks in a Suburban Area", Transportation Research Procedia, 39, pp. 554-564. https://doi.org/10.1016/j.trpro.2019.06.057

Yi, S., Nelson, P. W., Ulsoy, A. G. (2010) "Time-Delay Systems: Analysis and Control Using the Lambert W Function", World Scientific, Singapore.

https://doi.org/10.1142/7759 